OPEN ACCESS

Edited by:

Xiaomin Li,

Fudan University, China

Reviewed by:

Yongqiang Dong,

Fuzhou University, China

Helin Niu,

Anhui University, China

*Correspondence:

Zhengchun Yang

yangzhengchuntjut@163.com

Specialty section:

This article was submitted to

Nanoscience,

a section of the journal

Frontiers in Chemistry

Received: 10 December 2019

Accepted: 15 May 2020

Published: 30 June 2020

Citation:

Niu $H$, Yang $X$, Wang $Y, L i M$.

Zhang G, Pan P, Qi Y, Yang Z, Wang J

and Liao $Z$ (2020)

Electrochemiluminescence Detection

of Sunset Yellow by Graphene

Quantum Dots. Front. Chem. 8:505.

doi: 10.3389/fchem.2020.00505

\section{Electrochemiluminescence Detection of Sunset Yellow by Graphene Quantum Dots}

\author{
Huimin Niu ${ }^{1}$, Xin Yang ${ }^{1}$, Yilei Wang ${ }^{2}$, Mingchen $\mathrm{Li}^{1}$, Guangliang Zhang ${ }^{1}$, Peng Pan ${ }^{1}$, \\ Yangyang $\mathrm{Qi}^{1}$, Zhengchun Yang ${ }^{1 *}$, John Wang $^{3}$ and Zhenyu Liao ${ }^{4,5}$ \\ 1 Tianjin Key Laboratory of Film Electronic and Communication Devices, Advanced Materials and Printed Electronics Center, \\ School of Electrical and Electronic Engineering, Tianjin University of Technology, Tianjin, China, ${ }^{2}$ Tianjin Key Laboratory of \\ Organic Solar Cells and Photochemical Conversion, School of Chemistry and Chemical Engineering, Tianjin University of \\ Technology, Tianjin, China, ${ }^{3}$ Department of Materials Science and Engineering, National University of Singapore, Singapore, \\ Singapore, ${ }^{4}$ Pony Testing International Group, Tianjin, China, ${ }^{5}$ Tianjin Food Safety Inspection Technology Institute, Tianjin, \\ China
}

Use of food additives, such as colorants and preservatives, is highly regulated because of their potential health risks to humans. Therefore, it is important to detect these compounds effectively to ensure conformance with industrial standards and to mitigate risk. In this paper, we describe the preparation and performance of an ultrasensitive electrochemiluminescence (ECL) sensor for detecting a key food additive, sunset yellow. The sensor uses graphene quantum dots (GQDs) as the luminescent agent and potassium persulfate as the co-reactant. Strong and sensitive ECL signals are generated in response to trace amounts of added sunset yellow. A detection limit (signal-to-noise ratio $=3$ ) of $7.6 \mathrm{nM}$ and a wide linear range from $2.5 \mathrm{nM}$ to $25 \mu \mathrm{M}$ are demonstrated. A further advantage of the method is that the luminescent reagents can be recycled, indicating that the method is sustainable, in addition to being simple and highly sensitive.

Keywords: graphene quantum dots (GQDs), electrochemiluminescence (ECL), sunset yellow, food safety, sensor

\section{INTRODUCTION}

In recent years, there have been growing concerns about food safety and the effects of certain food additives on human health in particular (Gan et al., 2013). Multiple studies have shown that excessive food additives, particularly synthetic colorants, often leads to cancer and other fatal effects, after a series of chemical reactions (Rovina et al., 2017). One common food additive, better known as FD\&C Yellow No. 6 or sunset yellow, is a synthetic food colorant that is used widely (Vladislavić, 2018). Its strong and bright color, chemical stability, and low price have favored its use in the food industry (Zhang et al., 2010). However, the chemical functionalities of sunset yellow, i.e., its aromaticity and presence of an azo $(\mathrm{N}=\mathrm{N})$ moiety, can adversely affect human health if not controlled properly (Qiu et al., 2016; Sun et al., 2019). Food products with excessive added sunset yellow can cause allergies, anxiety, migraine, asthma, diarrhea, eczema, and other symptoms and can even lead to cancer (Yadav et al., 2012; Senthilkumar et al., 2013; Ding et al., 2019). Therefore, there is a clear need for a reliable technique that can accurately detect the amount of sunset yellow in food.

While there are already various methods for detecting sunset yellow, including highperformance liquid chromatography (HPLC) (Minioti et al., 2007; Alves et al., 2008; Sha et al., 2014), fluorescence spectroscopy (Yuan et al., 2016), UV-vis spectroscopy (Zou et al., 2013), 
and electrochemistry (Tran et al., 2019), these techniques are equipment-based and require properly trained operators and specialized equipment. Moreover, the detection limits are largely dependent on the operating conditions, and the overall costs are relatively high because organic solvents are required (Niu et al., 2013). A viable alternative to these existing approaches is electrochemiluminescence (ECL)-based detection, which has attracted much attention owing to simple instrumentation, operational convenience, low energy consumption, low environmental impact, and simple operation (Li S. et al., 2019).

ECL-based analysis uses electrochemically generated light to detect the presence of target analytes, similar to detection based on chemiluminescence and fluorescence (Liang et al., 2018). It has already been successfully employed for the detection of nitroaromatic, phenolic, and polycyclic aromatic compounds, among others (Zhang et al., 2014; Li S. et al., 2019). ECL reagents typically include luminol, ruthenium compounds, and quantum dots (Hao et al., 2017). In this study, we used graphene quantum dots (GQDs) as an ECL reagent to detect sunset yellow. GQDs are a class of quasi-zero-dimensional nanomaterials with diameters of $<100 \mathrm{~nm}$ (Zhang et al., 2016). Owing to their small size, they have novel physical and chemical properties (Li et al., 2013). Compared with luminescent materials and other quantum dots, GQDs have higher specific surface area, water solubility, stability, and biocompatibility, along with other beneficial properties such as low physiological toxicity and ease of modification (Gan et al., 2013; Zhang et al., 2015; Liu et al., 2016). These advantages have led to the widespread application of GQDs in bio-imaging (Zhu et al., 2012), photoelectron devices (Gupta et al., 2011), photocatalysis (Gupta et al., 2015), and chemical sensors (Chen et al., 2018).

By applying GQDs to ECL, we can detect sunset yellow with high sensitivity. The ECL-based technique is more efficient and faster than other detection methods. Further, the reagent can be recycled and stored, and the luminescence image is stable. Moreover, it can also be used as a highly accessible and effective technique for the detection of other small molecular analytes in food sources (Ding et al., 2019).

\section{EXPERIMENTAL}

\section{Reagents and Chemicals}

GQDs were purchased from Nanjing XFNANO Material Technology Company. Sunset yellow was purchased from Shanghai Yuanye Biotechnology Co., Ltd. All other chemicals were purchased from Sigma-Aldrich. All the chemicals were used as received without further purification.

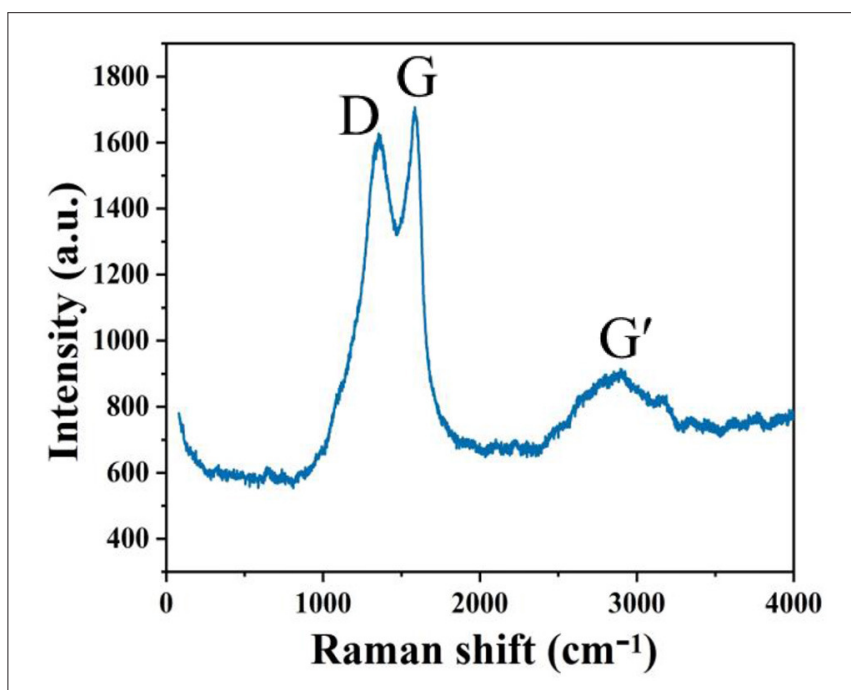

FIGURE 2 | Raman spectrum of GQDs in an aqueous suspension.
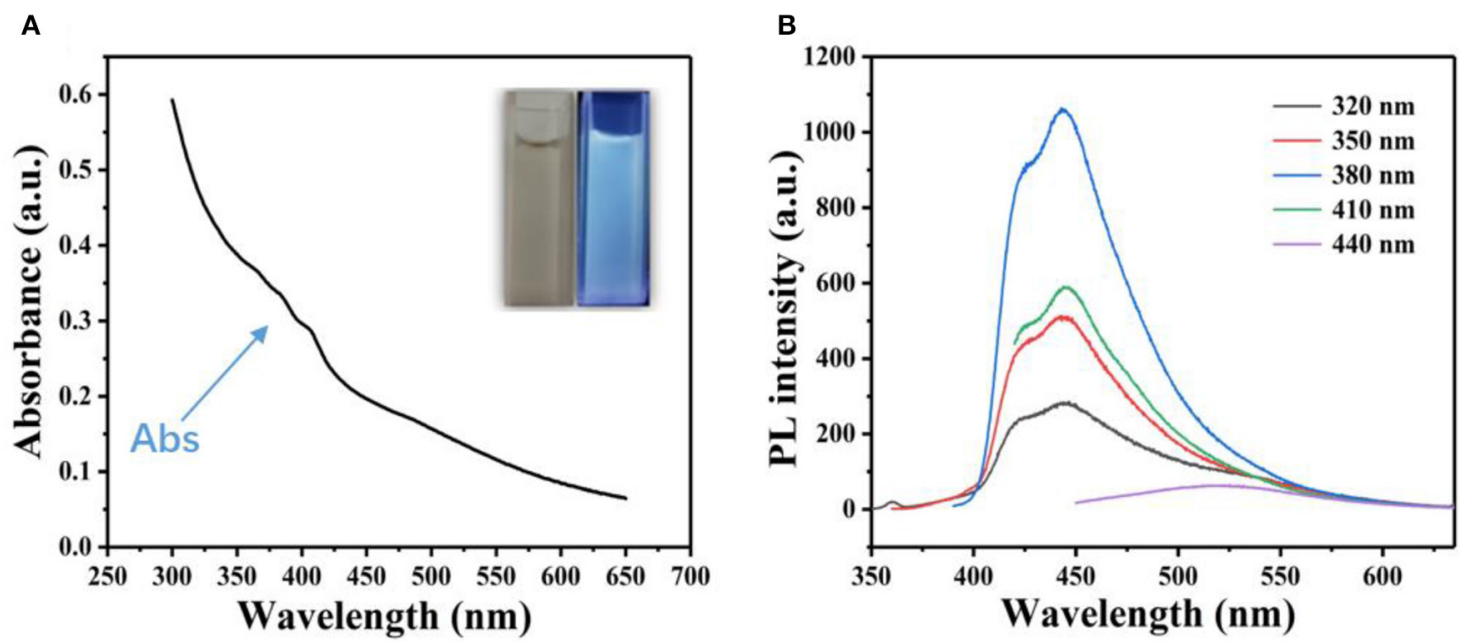

FIGURE 1 | Spectrophotometric characterization of GQDs. (A) UV spectrum of an aqueous suspension of GQDs. Inset: aqueous suspension of GQDs under natural light (left) and blue fluorescence upon excitation by a $365 \mathrm{~nm}$ UV lamp (right). (B) Fluorescence spectra of GQDs at different excitation wavelengths. 
A $0.08 \mathrm{M} \mathrm{KCl}$ solution and phosphate-buffered saline (PBS) $(0.01 \mathrm{M}, \mathrm{pH} 7)$ was used as the electrolyte, and $0.05 \mathrm{M} \mathrm{K}_{2} \mathrm{~S}_{2} \mathrm{O}_{8}$ was used as the co-reactant.

\section{Apparatus}

UV absorption spectra were measured on an Evolution 220 UV-

vis spectrophotometer (Thermo Scientific). Fluorescence

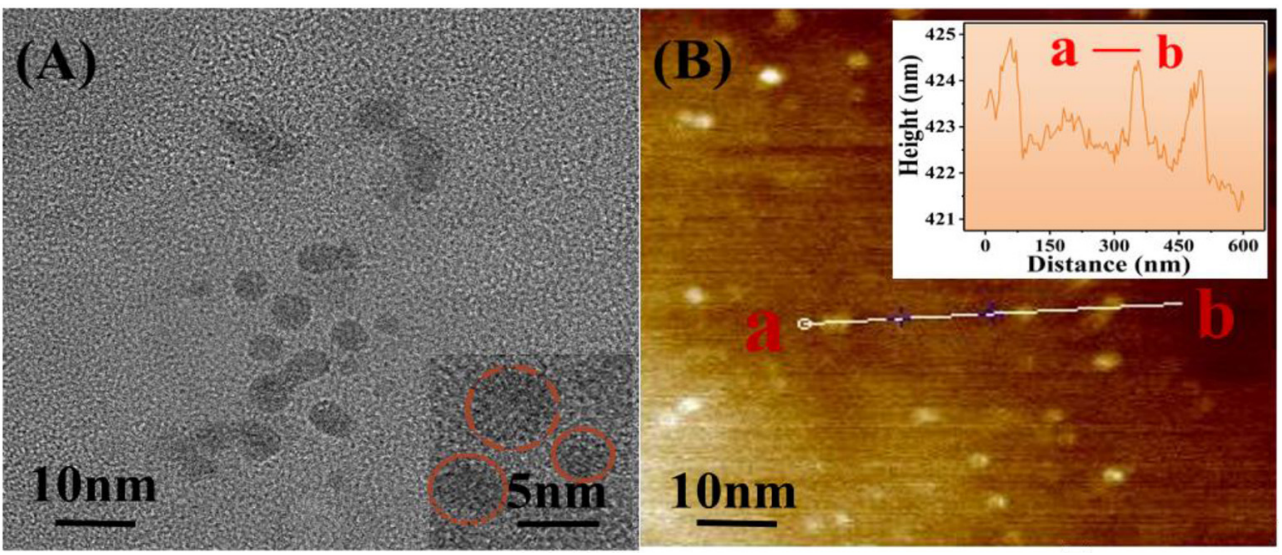

FIGURE 3 | Morphological characterization of GQDs using TEM and AFM. (A) TEM image with the inset showing the GQDs at 2x magnification. (B) AFM image with the height profile of GQDs shown in the inset.

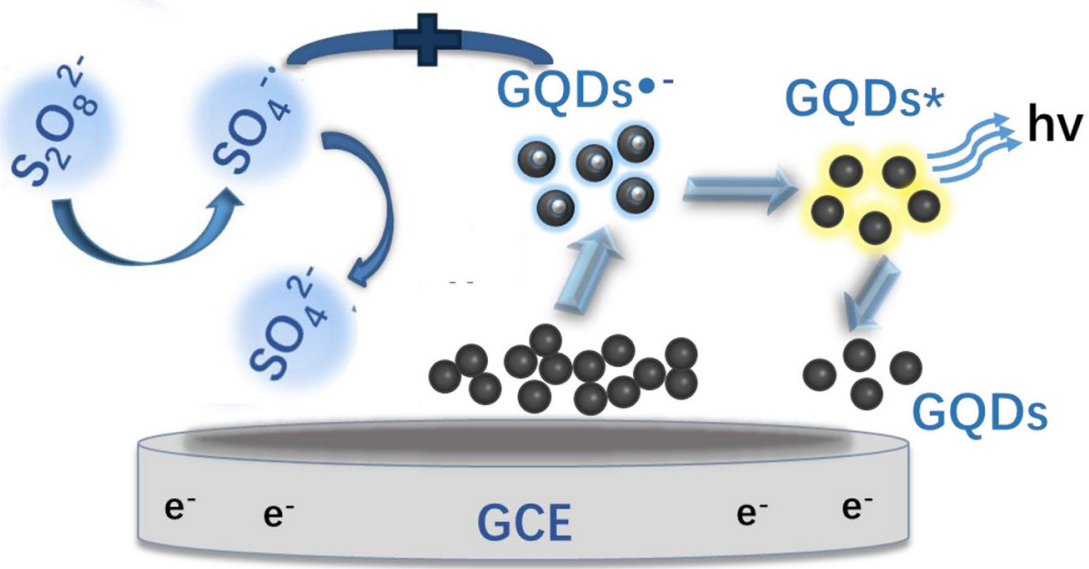

FIGURE 4 | ECL mechanism of the GQD sensor. GQDs*: excited-state GQDs; $\mathrm{h}^{+}$: positive holes; GCE, glassy carbon electrode.
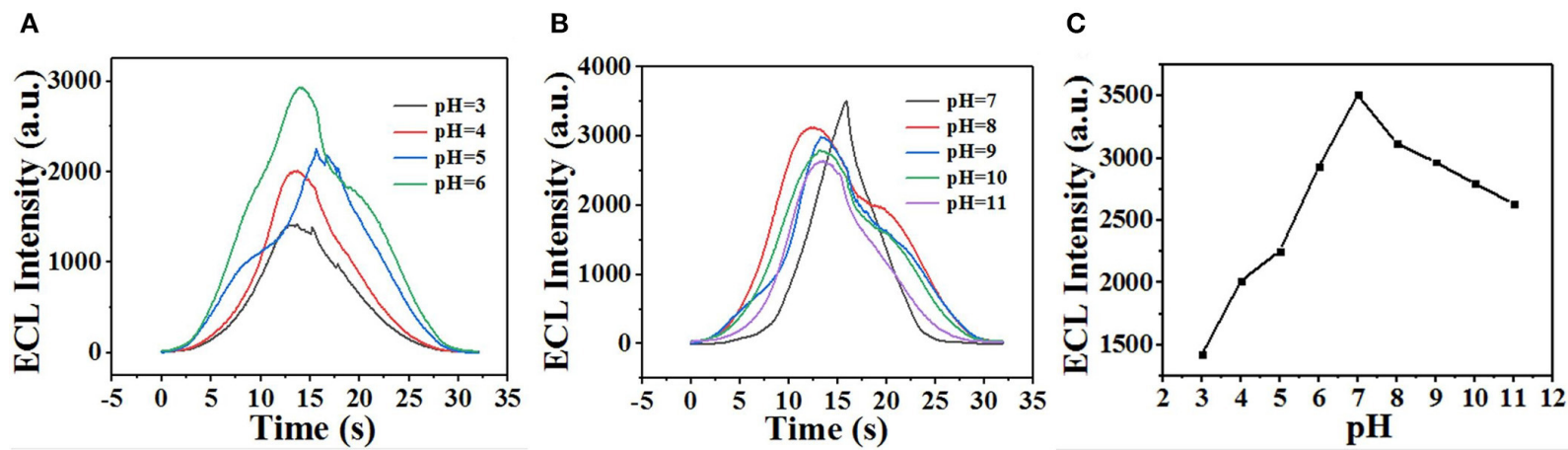

FIGURE 5 | (A,B) Effect of pH on the ECL performance. (C) ECL intensity as a function of pH. 
properties were evaluated on an F-7000 fluorescence spectrophotometer (Hitachi). Raman spectroscopy was performed at room temperature on a high-resolution laser confocal micro-Raman spectrometer (LabRAM HR Evolution, HORIBA). The morphology of the GQDs was characterized by transmission electron microscopy (TEM) and atomic force microscopy (AFM) using a Talos F200 X microscope (FEI) and an Evolution microscope (HORIBA JOBIN YVON S.A.S.), respectively. ECL measurements were conducted using an MPI-EII workstation (Xi'an Remax Electronic Science \& Technology Co., Ltd., China).

\section{ECL Measurement Prcedure}

ECL voltage curves were obtained using the MPI-EII workstation. Cyclic voltammetry (CV) was conducted using a conventional three-electrode system consisting of a glassy carbon electrode (GCE) (working electrode), $\mathrm{Ag} / \mathrm{AgCl}$ in saturated $\mathrm{KCl}$ solution (reference electrode), and a platinum wire (counter electrode).

The electrode surface was pretreated before use. The surface of the GCE was polished with 0.3 and $0.05 \mu \mathrm{m} \mathrm{Al}_{2} \mathrm{O}_{3}$ on buckskin cloth and then rinsed with deionized water. All three electrodes were then sonicated for $5 \mathrm{~min}$ in ethanol and deionized water and dried at room temperature.

$\mathrm{CV}$ measurements were performed in $0.01 \mathrm{M}$ PBS ( $\mathrm{pH} 7$ ) mixed with $0.08 \mathrm{M} \mathrm{KCl}$ as the supporting electrolyte and $0.05 \mathrm{M}$ $\mathrm{K}_{2} \mathrm{~S}_{2} \mathrm{O}_{8}$ as the co-reactant. For the ECL measurements, GQDs $\left(0.1 \mathrm{mgmL}^{-1}, 200 \mu \mathrm{L}\right)$ were mixed with a solution of $0.05 \mathrm{M}$ $\mathrm{K}_{2} \mathrm{~S}_{2} \mathrm{O}_{8}$ and $0.08 \mathrm{M} \mathrm{KCl}$ in PBS $(1,800 \mu \mathrm{L})$ at a ratio of 1:9. The sunset yellow solutions of concentrations in the range of $2.5 \times 10^{-9}$ to $2.5 \times 10^{-5} \mathrm{M}$ in PBS were prepared from a stock solution. PBS solutions from $\mathrm{pH} 3$ to 11 were prepared to detect the influence of $\mathrm{pH}$ on luminous intensity. The effect of different values of $\mathrm{pH}$ on light intensity was detected with a sunset yellow concentration of $0.25 \mu \mathrm{M}$ under the optimized conditions (GQDs, $0.1 \mathrm{mgmL}^{-1}$; co-reactant, $0.05 \mathrm{M} \mathrm{K}_{2} \mathrm{~S}_{2} \mathrm{O}_{8}$; supporting electrolyte, $0.08 \mathrm{M} \mathrm{KCl}$; scan rate, $0.1 \mathrm{Vs}^{-1}$ ). All of the experiments were performed within the potential range of -2.2 to $-0.6 \mathrm{~V}$.

\section{RESULTS AND DISCUSSION}

\section{Characterization of GQDs}

The GQDs were characterized by UV-vis spectrophotometry (Figure 1A); a weak absorption peak was observed at $375 \mathrm{~nm}$. The GQDs also exhibited photoluminescence (PL), as evidenced by the blue fluorescence emitted under UV illumination at $365 \mathrm{~nm}$ (Figure 1A, inset). The fluorescence spectra of the GQDs were obtained for different excitation wavelengths (Figure 1B). The emission wavelength of the GQDs was dependent on the excitation wavelength, which is consistent with the known characteristics of GQDs (Zhou et al., 2019). For example, when the excitation wavelength was increased from 320 to $440 \mathrm{~nm}$, the PL peak is red-shifted (Zhou et al., 2009), with the strongest peak appearing at $450 \mathrm{~nm}$ upon excitation at $380 \mathrm{~nm}$.

The Raman spectrum of the GQDs shows G, D, and G' peaks (Figure 2); the strongest peak, referred to as the $G$ peak (the main characteristic peak of graphene), which is attributed to the in-plane vibration of the $\mathrm{sp}^{2}$ carbon atoms, appeared at 1,583 $\mathrm{cm}^{-1}$ (Mishra and Bhat, 2019). The D peak observed at 1,353 $\mathrm{cm}^{-1}$ is generally considered the disordered vibration peak of graphene. There is an appreciable loss of the graphitic layered structure, as evidenced by the almost 1:1 ratio of the $\mathrm{D}$ and $\mathrm{G}$ band intensities. The weak broad band at $\sim 2,896 \mathrm{~cm}^{-1}$, i.e., the G' peak (2D peak), is a two-fidelity resonance second-order Raman peak that characterizes a particular form of structure (interlayer stacking of carbon atoms) in graphene (Sun et al., 2019).

The morphology of the GQDs was then characterized using TEM and high-resolution AFM (Figure 3). TEM studies revealed that the GQDs are relatively uniform in size (average diameter $=5 \mathrm{~nm}$ ) and are distributed in a single layer (Li et al., 2012). The crystal lattice of the GQDs can be clearly seen in Figure 3A (inset). From the AFM image (Figure 3B), the topographic heights of the GQDs were measured to be between 0.5 and
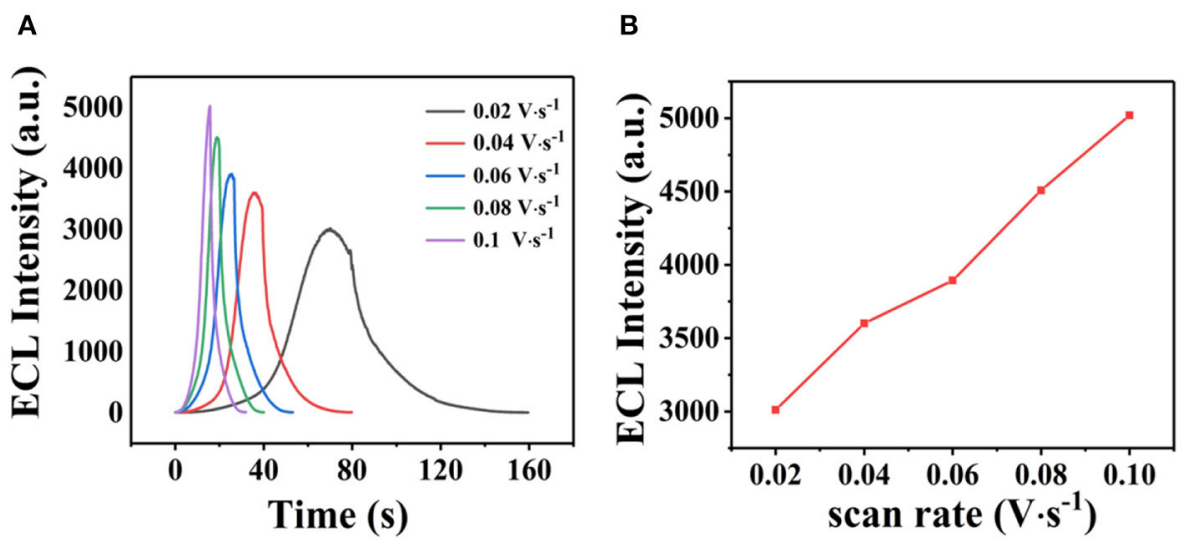

FIGURE 6 | (A) Effect of scan rate on the ECL performance and (B) ECL intensity as a function of scan rate. 
$2 \mathrm{~nm}$, with the average height being $1.2 \mathrm{~nm}$ (Figure 3B, inset), which suggests the presence of single or bi-layers in GQDs (Akilimali et al., 2020).
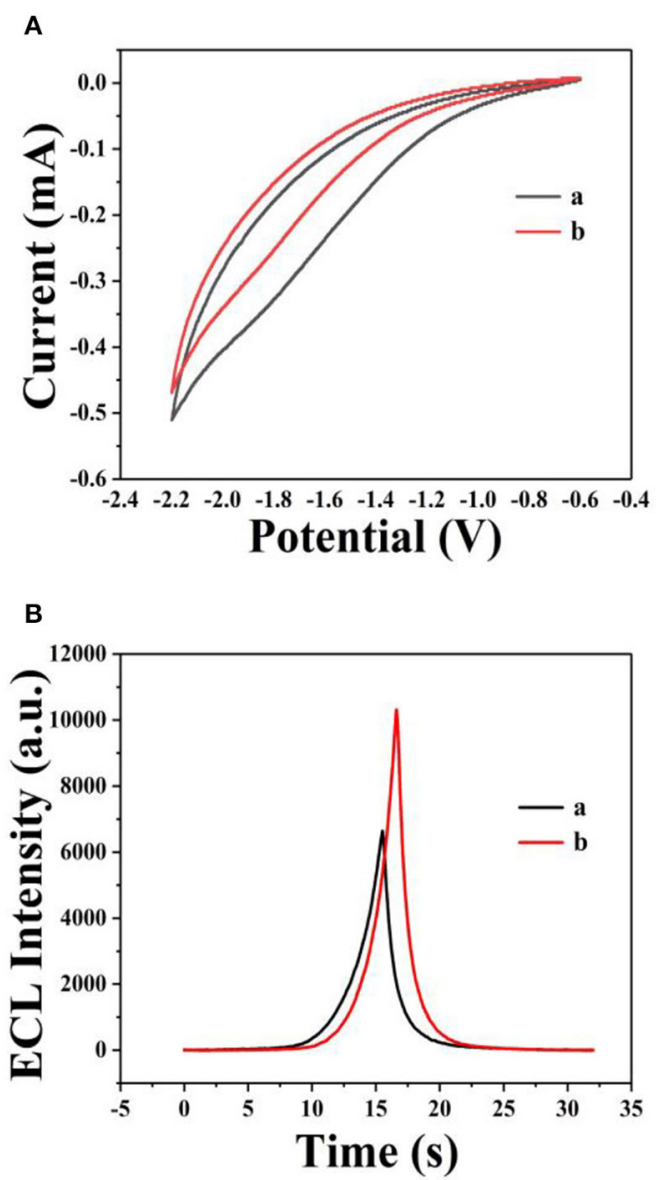

c

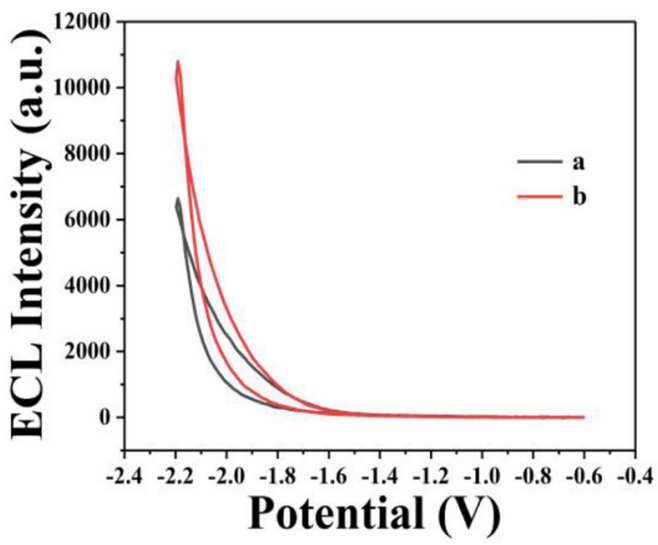

FIGURE 7 | ECL responses from GQDs. Cyclic voltammograms (A) and ECL responses (B) of the GQDs/GCE electrode (a) without sunset yellow and (b) in the presence of $0.025 \mu \mathrm{M}$ solution of sunset yellow. (C) ECL response of the GQDs/GCE electrode: (a) without sunset yellow and (b) in the presence of $0.025 \mu \mathrm{M}$ solution of sunset yellow. Optimized conditions used for the reactions: GQDs, $0.1 \mathrm{mgmL}^{-1}$; co-reactant, $0.05 \mathrm{M} \mathrm{K}_{2} \mathrm{~S}_{2} \mathrm{O}_{8}$; supporting electrolyte, $0.08 \mathrm{M} \mathrm{KCl}$; PBS (pH 7); scan rate, $0.1 \mathrm{Vs}^{-1}$.

\section{Mechanism of the GQD Sensor to Detect}

\section{Sunset Yellow}

The ECL mechanism of the GQD sensor is schematized in Figure 4. Initially, reduction of $\mathrm{K}_{2} \mathrm{~S}_{2} \mathrm{O}_{8}$ is performed to

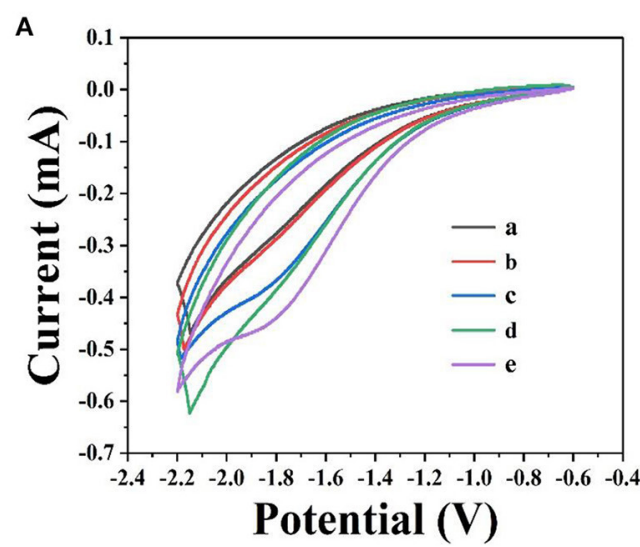

B

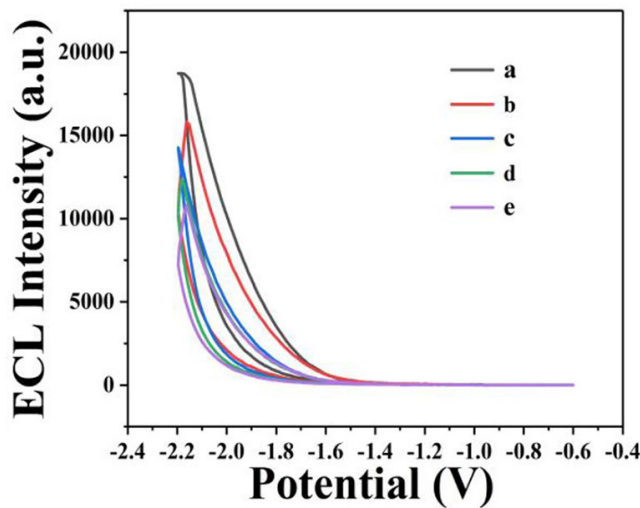

C

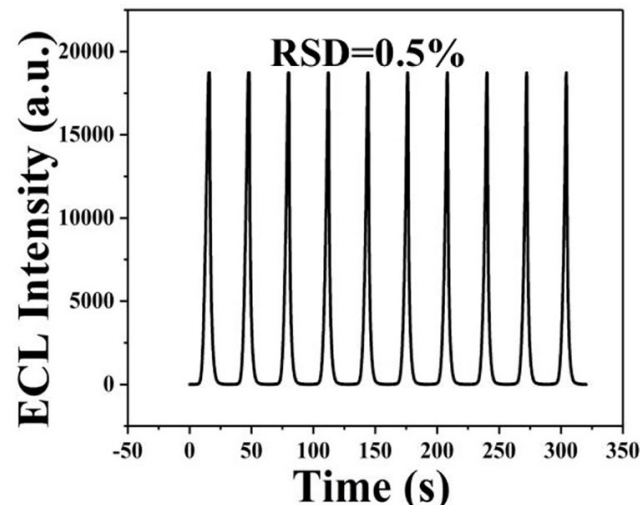

FIGURE 8 | Detection of sunset yellow by ECL using GQDs. Cyclic voltammograms (A) and ECL response (B) of the GQDs/GCE electrode at different concentrations of sunset yellow: (a) $25 \mu \mathrm{M}$, (b) $2.5 \mu \mathrm{M}$, (c) $0.25 \mu \mathrm{M}$, (d) $0.025 \mu \mathrm{M}$, and (e) $0.0025 \mu \mathrm{M}$. (C) ECL responses of the biosensor to sunset yellow $(25 \mu \mathrm{M})$ over 10 successive cycles. Optimized conditions used for the reaction: GQDs, $0.1 \mathrm{mgmL}^{-1}$; co-reactant, $0.05 \mathrm{M} \mathrm{K}_{2} \mathrm{~S}_{2} \mathrm{O}_{8}$; supporting electrolyte, 0.08 $\mathrm{M} \mathrm{KCl}$; PBS buffer ( $\mathrm{pH} 7$ ); scan rate, $0.1 \mathrm{Vs}^{-1}$. 
form $\mathrm{SO}_{4}^{2-}$ and $\mathrm{SO}_{4}^{-}$, while the GQDs are simultaneously reduced to anionic radical GQDs ${ }^{-}$. The strongly oxidizing $\mathrm{SO}^{-}$ radicals react with the GQDs ${ }^{-}$radicals via an electron-transfer annihilation process to produce the excited state of GQDs (GQDs*). Finally, the GQDs* emit light and return to the ground state (Li et al., 2012; Hu et al., 2019; Li M. et al., 2019). As shown in Figure 7B, there is a very obvious ECL curve, and the ECL intensity is high enough. As shown in Figures 7A-C, when $0.025 \mu \mathrm{M}$ sunset yellow is added, the current and the ECL intensity are clearly increased compared to when sunset yellow is not added. Sunset yellow was analyzed by the ECL signal of the $\mathrm{GQD} / \mathrm{K}_{2} \mathrm{~S}_{2} \mathrm{O}_{8}$ system, and the possible mechanism was proved through ECL and CV curves. Without adding sunset yellow, the electrons of the system come from the electrode. When sunset yellow is added, sunset yellow loses electrons and generates a new substance. The lost electrons are provided to the graphene quantum dot system, so GQD* in the system increases (Gan et al., 2013). This process is described by Equation (1-5):

$$
\begin{aligned}
\mathrm{S}_{2} \mathrm{O}_{8}{ }^{2-}+\mathrm{e}^{-} & \rightarrow \mathrm{SO}_{4}{ }^{2-}+\mathrm{SO}_{4}{ }^{--} \\
\mathrm{GQDs}+\mathrm{e}^{-} & \rightarrow \mathrm{GQDS}^{\bullet-} \\
\mathrm{GQDs}^{\bullet-}+\mathrm{SO}_{4}{ }^{\bullet-} & \rightarrow \mathrm{GQDs} \mathrm{s}^{*}+\mathrm{SO}_{4}{ }^{2-} \\
\mathrm{GQDs}^{*} & \rightarrow \mathrm{GQDs}+h v
\end{aligned}
$$

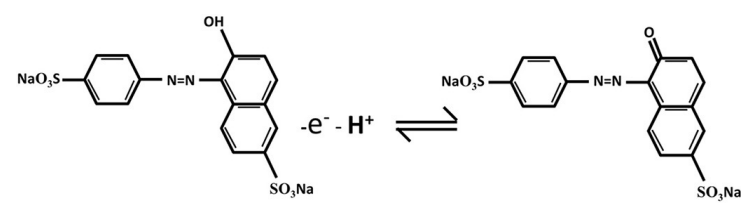

\section{Detection of Sunset Yellow by ECL Using GQDs}

The ECL behavior of GQDs was investigated through CV using a cathodic co-reactant $\left(\mathrm{K}_{2} \mathrm{~S}_{2} \mathrm{O}_{8}\right)$. The scan rate in the CV method and the $\mathrm{pH}$ of $\mathrm{PBS}$ were optimized at room temperature to determine the best conditions for detecting sunset yellow. Figures $5 \mathbf{A}, \mathbf{B}$ show the influence of $\mathrm{pH}$ from 3 to 11 on the ECL intensity. Figure 5C shows that the ECL intensity increases with $\mathrm{pH}$ in the range of 3 to 7 and then decreases at $\mathrm{pH}$ values beyond 7. When the $\mathrm{pH}$ was 7 , the ECL intensity reached the maximum. Therefore, the optimal pH of PBS is 7 (Cheng et al., 2012). In addition, the ECL luminous intensity is different at different scan rates. Figures $6 \mathrm{~A}, \mathrm{~B}$ illustrate that the ECL intensity strengthens in the range of $0.02-0.1 \mathrm{~V} \bullet \mathrm{s}^{-1}$, indicating that the excited-state substance is insufficiently produced at low scan rates. Therefore, the optimal experimental condition was a scan rate of $0.1 \mathrm{~V} \bullet \mathrm{s}^{-1}$

\begin{tabular}{|c|c|c|c|c|}
\hline Electrode & Method & Linear range & LOD & References \\
\hline- & UV-vis & $2-40 \mu \mathrm{gmL}^{-1}$ & - & $\begin{array}{l}\text { Sorouraddin } \\
\text { et al., } 2011\end{array}$ \\
\hline- & HPLC & $0.05-300 \mathrm{ngmL}^{-1}$ & $0.015 \mathrm{ngmL}^{-1}$ & 1 Wu et al., 2013 \\
\hline- & Spectrometry & $4.42-17.68 \mu \mathrm{M}$ & $193.0 \mathrm{nM}$ & Dinç, 2002 \\
\hline- & Fluorescence & $0.3-8.0 \mu \mathrm{M}$ & $79.6 \mathrm{nM}$ & $\begin{array}{l}\text { Yuan et al., } \\
2016\end{array}$ \\
\hline $\begin{array}{l}\mathrm{Fe}_{3} \mathrm{O}_{4} @ \mathrm{rGO} / \\
\mathrm{GCE}\end{array}$ & Electrochemistry & $0.05-50 \mu \mathrm{M}$ & $50 \mathrm{nM}$ & Han et al., 2014 \\
\hline $\mathrm{Au} / \mathrm{GO}$ & Electrochemistry & $0.01-3.0 \mu \mathrm{M}$ & $2.4 \mathrm{nM}$ & $\begin{array}{l}\text { Deng et al., } \\
2016\end{array}$ \\
\hline $\mathrm{ERGO/GCE}$ & Electrochemistry & $0.05-1.0 \mu \mathrm{M}$ & $19.2 \mathrm{nM}$ & Tran et al., 2019 \\
\hline $\begin{array}{l}\text { GO/ } \\
\text { MWCNTs/ } \\
\text { GCE }\end{array}$ & Electrochemistry & $0.09-8.0 \mu \mathrm{M}$ & $25 \mathrm{nM}$ & $\begin{array}{l}\text { Vladislavić, } \\
2018\end{array}$ \\
\hline $\begin{array}{l}\text { MGO/B-CD/ } \\
\text { IL/AuNPs/ } \\
\text { GCE }\end{array}$ & Electrochemistry & $0.005-2 \mu \mathrm{M}$ & $2 \mathrm{nM}$ & Li et al., 2016 \\
\hline GQDs/GCE & $E C L$ & $0.0025-25$ & $7.6 \mathrm{nM}$ & This work \\
\hline
\end{tabular}
(Dai et al., 2010). The GQD system emits stably under the

TABLE 1 | Comparison of the system described herein with other reported methods used to detect sunset yellow.

rGO, reduced graphene oxide; GO, graphene oxide; MWCNT, multiwalled carbon nanotube; $\beta$-CD, $\beta$-cyclodextrin; AuNP, gold nanoparticle; ERGO, exfoliated reduced graphene oxide.

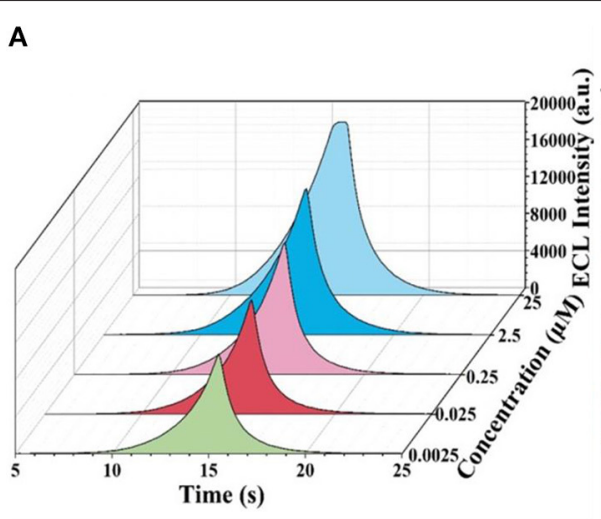

B

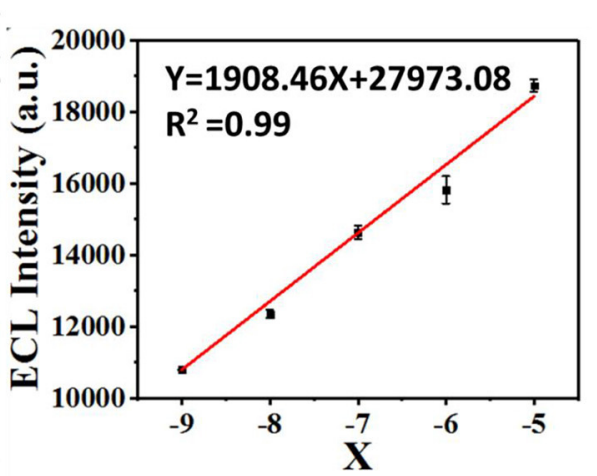

FIGURE 9 | Determination of the limit of ECL detection of sunset yellow. (A) ECL intensities over time at different concentrations of sunset yellow. (B) Logarithmic calibration curve of the sunset yellow biosensor $[X=L g(C / 2.5)]$. 


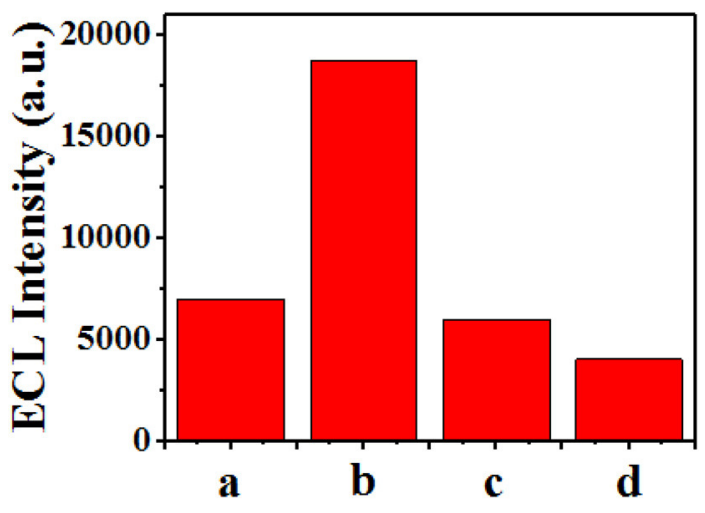

FIGURE 10 | Demonstration of the selectivity of the ECL sensor. Response of the sensor when different substances were added: (a) none, (b) sunset yellow, (c) amaranth, and (d) sodium citrate.

optimized conditions [GQDs, $0.1 \mathrm{mgmL}^{-1}$; co-reactant, $0.05 \mathrm{M}$ $\mathrm{K}_{2} \mathrm{~S}_{2} \mathrm{O}_{8}$; supporting electrolyte, $0.08 \mathrm{M} \mathrm{KCl}$; PBS buffer ( $\mathrm{pH} \mathrm{7)}$; scan rate, $0.1 \mathrm{Vs}^{-1}$ ]. The black and red curves in Figure $7 \mathrm{~A}$ show the correspondences between the current and voltage in the absence and presence of $0.025 \mu \mathrm{M}$ solution of sunset yellow, respectively. Upon adding sunset yellow, there was a significant increase in the ECL signal intensity (Figure 7B). Both the current and ECL signal intensity increased with increasing sunset yellow concentration (Figures 8A,B, respectively), indicating that the ECL system can differentiate the sunset yellow concentration. The stability of the ECL system is shown in Figure 8C.

Upon the addition of sunset yellow, the lost electrons are supplied to the system, generating the original system to produce more intermediate states. Therefore, the ECL signal increases with increasing concentration of sunset yellow in the range from 0.0025 to $25 \mu \mathrm{M}$ (Figure 9A). A linear fit was obtained between the logarithm of the sunset yellow concentration and ECL intensity (Figure 9B), and the limit of detection (LOD) was determined to be $7.6 \mathrm{nM}$ (signal-to-noise ratio $=3$ ). A comparison between the system developed herein and previously reported sensors shows that this new sensor performs better than most existing sensors in the detection of sunset yellow (Table 1).

\section{Selective Detection of Sunset Yellow by ECL Using GQDs}

Further, different substances, including sunset yellow, amaranth, and sodium citrate, were detected using the ECL sensor (Figure 10). Under the same experimental conditions, different

\section{REFERENCES}

Akilimali, R., Selopal, G. S., Benetti, D., Mohammadnezhad, M., Zhao, H., Wang, Z. M., et al. (2020). Graphene nanoribbon-TiO2-quantum dots hybrid photoanode to boost the performance of photoelectrochemical for hydrogen generation. Catalysis Today 340, 161-169. doi: 10.1016/j.cattod.2018.10.052

Alves, S. P., Brum, D. M., Branco de Andrade, É. C., and Pereira Netto, A. D. (2008). Determination of synthetic dyes in selected detection substances of the same concentration $(25 \mu \mathrm{M})$ were added, and the measured luminous intensity is shown in Figure 10. When sunset yellow was added, the light intensity increased significantly. However, when the other two substances were added, there was a small decrease in the light intensity. This result demonstrates that this method has preliminary selectivity in the detection of sunset yellow.

\section{CONCLUSIONS}

Herein, we demonstrated a new, simple ECL sensor using GQDs that can be used to detect the food additive, sunset yellow. The ECL signal of the GQDs changes with the addition of sunset yellow. Under optimized conditions, the GQD sensor shows good linearity in the detection of sunset yellow in the concentration range of $0.0025-25 \mu \mathrm{M}$ with a detection limit of $7.6 \mathrm{nM}$. Therefore, the method described herein is a highly sensitive one for detecting sunset yellow. This study also provides a basis for rapid screening for potentially harmful food additives.

\section{DATA AVAILABILITY STATEMENT}

All datasets generated for this study are included in the article/supplementary material.

\section{AUTHOR CONTRIBUTIONS}

$\mathrm{HN}, \mathrm{XY}$, and ML finished the material characterizations and electrochemiluminescence measurements. YW designed the photoluminescence characterizations. GZ and PP gave guidance about the electrochemical reactions. YQ analyzed the electrochemiluminescence mechanism. The manuscript was drafted by $\mathrm{HN}$ and $\mathrm{ZY}$, while was revised by JW. ZL gave rise to the research meanings in the area of food safety. All authors critically revised the manuscript, approved the final version, and agreed to be accountable for all aspects of the work.

\section{FUNDING}

This research was funded by Tianjin Development Program for Innovation and Entrepreneurship, Tianjin Natural Science Foundation (Grant Nos. 18JCZDJC99800, 17JCQNJC00900), National Natural Science Foundation of China (Grant No. 51502203), Tianjin Young Overseas High-level Talent Plans (Grant No. 01001502), Tianjin Science and Technology Foundation (Grant No. 17ZXZNGX00090), and Tianjin Distinguished Professor Foundation of Young Researchers. 
and its application in selective sensing $\mathrm{Cu}^{2+}$. Anal. Chem. 84, 4754-4759. doi: $10.1021 / \mathrm{ac} 300205 \mathrm{w}$

Dai, H., Chi, Y. W., Wu, X. P., Wang, Y. M., Wei, M. D., and Chen, G. N. (2010). Biocompatible electrochemiluminescent biosensor for choline based on enzyme/titanate nanotubes/chitosan composite modified electrode. Biosens. Bioelectr. 25, 1414-1419. doi: 10.1016/j.bios.2009.10.042

Deng, K., Li, C., Li, X., and Huang, H. (2016). Simultaneous detection of sunset yellow and tartrazine using the nanohybrid of gold nanorods decorated graphene oxide. J. Electroanal. Chem. 780, 296-302. doi: 10.1016/j.jelechem.2016.09.040

Dinç, E. (2002). Spectrophotometric multicomponent determination of sunset yellow, tartrazine and allura red in soft drink powder by double divisor-ratio spectra derivative, inverse least-squares and principal component regression methods. Talanta 58, 579-594. doi: 10.1016/S0039-9140(02)00320-X

Ding, Z., Deng, P., Wu, Y., Tian, Y., Li, G., Liu, J., et al. (2019). A novel modified electrode for detection of the food colorant sunset yellow based on nanohybrid of $\mathrm{MnO}(2)$ nanorods-decorated electrochemically reduced graphene oxide. Molecules 24:1178. doi: 10.3390/molecules 24061178

Gan, T., Sun, J., Meng, W., Song, L., and Zhang, Y. (2013). Electrochemical sensor based on graphene and mesoporous $\mathrm{TiO} 2$ for the simultaneous determination of trace colourants in food. Food Chem. 141, 3731-3737. doi: 10.1016/j.foodchem.2013.06.084

Gupta, B. K., Kedawat, G., Agrawal, Y., Kumar, P., Dwivedi, J., and Dhawan, S. K. (2015). A novel strategy to enhance ultraviolet light driven photocatalysis from graphene quantum dots infilled $\mathrm{TiO}_{2}$ nanotube arrays. RSC Adv. 5, 10623-10631. doi: 10.1039/C4RA14039G

Gupta, V., Chaudhary, N., Srivastava, R., Sharma, G. D., Bhardwaj, R., and Chand, S. (2011). Luminscent graphene quantum dots for organic photovoltaic devices. J. Am. Chem. Soc. 133, 9960-9963. doi: 10.1021/ja2036749

Han, Q., Wang, X., Yang, Z., Zhu, W., Zhou, X., and Jiang, H. (2014). $\mathrm{Fe}_{3} \mathrm{O}_{4} @ \mathrm{rGO}$ doped molecularly imprinted polymer membrane based on magnetic field directed self-assembly for the determination of amaranth. Talanta 123, 101-108. doi: 10.1016/j.talanta.2014.01.060

Hao, N., Zhang, X., Zhou, Z., Hua, R., Zhang, Y., Liu, Q., et al. (2017). AgBr nanoparticles/3D nitrogen-doped graphene hydrogel for fabricating all-solidstate luminol-electrochemiluminescence Escherichia coli aptasensors. Biosens. Bioelectr. 97, 377-383. doi: 10.1016/j.bios.2017.06.025

Hu, F. X., Wang, J., Chen, S., and Rao, Q. (2019). Enhanced electrochemiluminescence from reduced graphene oxide-CdTe quantum dots for highly selective determination of copper ion. Luminescence 34, 666-672. doi: 10.1002/bio.3649

Li, F., Kou, L., Chen, W., Wu, C., and Guo, T. (2013). Enhancing the short-circuit current and power conversion efficiency of polymer solar cells with graphene quantum dots derived from double-walled carbon nanotubes. NPG Asia Mater. 5:e60. doi: 10.1038/am.2013.38

Li, J., Wang, X., Duan, H., Wang, Y., Bu, Y., and Luo, C. (2016). Based on magnetic graphene oxide highly sensitive and selective imprinted sensor for determination of sunset yellow. Talanta 147, 169-176. doi: 10.1016/j.talanta.2015.09.056

Li, L.-L., Ji, J., Fei, R., Wang, C.-Z., Lu, Q., Zhang, J.-R., et al. (2012). A facile microwave avenue to electrochemiluminescent two-color graphene quantum dots. Adv. Funct. Mater. 22, 2971-2979. doi: 10.1002/adfm.201200166

Li, M., Wang, C., Chen, L., and Liu, D. (2019). A novel electrochemiluminescence sensor based on resonance energy transfer system between nitrogen doped graphene quantum dots and boron nitride quantum dots for sensitive detection of folic acid. Anal. Chim. Acta 1090, 57-63. doi: 10.1016/j.aca.2019.09.018

Li, S., Liu, J., Chen, Z., Lu, Y., Low, S. S., Zhu, L., et al. (2019). Electrogenerated chemiluminescence on smartphone with graphene quantum dots nanocomposites for Escherichia Coli detection. Sens. Actuat. B Chem. 297:126811. doi: 10.1016/j.snb.2019.126811

Liang, X. L., Bao, N., Luo, X., and Ding, S. N. (2018). CdZnTeS quantum dots based electrochemiluminescent image immunoanalysis. Biosens. Bioelectr. 117, 145-152. doi: 10.1016/j.bios.2018.06.006

Liu, L., Wang, X., Ma, Q., Lin, Z., Chen, S., Li, Y., et al. (2016). Multiplex electrochemiluminescence DNA sensor for determination of hepatitis B virus and hepatitis $\mathrm{C}$ virus based on multicolor quantum dots and Au nanoparticles. Anal. Chim. Acta 916, 92-101. doi: 10.1016/j.aca.2016.02.024
Minioti, K. S., Sakellariou, C. F., and Thomaidis, N. S. (2007). Determination of 13 synthetic food colorants in water-soluble foods by reversed-phase highperformance liquid chromatography coupled with diode-array detector. Anal. Chim. Acta 583, 103-110. doi: 10.1016/j.aca.2006.10.002

Mishra, P., and Bhat, B. R. (2019). Aggregative ways of graphene quantum dots with nitrogen-rich edges for direct emission spectrophotometric estimation of glucose. Spectrochim. Acta A Mol. Biomol. Spectrosc. 223, 117-325. doi: $10.1016 /$ j.saa.2019.117325

Niu, X., Lan, M., Zhao, H., and Chen, C. (2013). Highly sensitive and selective nonenzymatic detection of glucose using three-dimensional porous nickel nanostructures. Anal. Chem. 85, 3561-3569. doi: 10.1021/ac3030976

Qiu, X., Lu, L., Leng, J., Yu, Y., Wang, W., Jiang, M., et al. (2016). An enhanced electrochemical platform based on graphene oxide and multi-walled carbon nanotubes nanocomposite for sensitive determination of Sunset Yellow and Tartrazine. Food Chem. 190, 889-895. doi: 10.1016/j.foodchem.2015.06.045

Rovina, K., Siddiquee, S., and Shaarani, S. M. (2017). Highly sensitive electrochemical determination of sunset yellow in commercial food products based on CHIT/GO/MWCNTs/AuNPs/GCE. Food Control 82, 66-73. doi: 10.1016/j.foodcont.2017.06.029

Senthilkumar, S., Prabhu, H. J., and Perumalsamy, M. (2013). Response surface optimization for biodegradation of textile azo dyes using isolated bacterial strain Pseudomonas sp. Arab. J. Sci. Eng. 38, 2279-2291. doi: 10.1007/s13369-012-0507-8

Sha, O., Zhu, X., Feng, Y., and Ma, W. (2014). Determination of sunset yellow and tartrazine in food samples by combining ionic liquid-based aqueous two-phase system with high performance liquid chromatography. J. Anal. Methods Chem. 2014:964273. doi: $10.1155 / 2014 / 964273$

Sorouraddin, M. H., Rostami, A., and Saadati, M. (2011). A simple and portable multicolour light emitting diode based photocolourimeter for the analysis of mixtures of five common food dyes. Food Chem. 127, 308-313. doi: 10.1016/j.foodchem.2010.12.124

Sun, S.-C., Hsieh, B.-C., and Chuang, M.-C. (2019). Electropolymerised-hemincatalysed reduction and analysis of tartrazine and sunset yellow. Electrochim. Acta 319, 766-774. doi: 10.1016/j.electacta.2019.07.014

Tran, Q. T., Phung, T. T., Nguyen, Q. T., Le, T. G., and Lagrost, C. (2019). Highly sensitive and rapid determination of sunset yellow in drinks using a low-cost carbon material-based electrochemical sensor. Anal. Bioanal. Chem. 411, 7539-7549. doi: 10.1007/s00216-019-02155-9

Vladislavić, N. (2018). Electroanalytical methods for determination of sunset yellow- a review. Int. J. Electrochem. Sci. 13, 7008-7019. doi: $10.20964 / 2018.07 .39$

Wu, H., Guo, J. B., Du, L. M., Tian, H., Hao, C. X., Wang, Z. F., et al. (2013). A rapid shaking-based ionic liquid dispersive liquid phase microextraction for the simultaneous determination of six synthetic food colourants in soft drinks, sugar- and gelatin-based confectionery by high-performance liquid chromatography. Food Chem. 141, 182-186. doi: 10.1016/j.foodchem.2013.03.015

Yadav, A., Kumar, A., Dwivedi, P. D., Tripathi, A., and Das, M. (2012). In vitro studies on immunotoxic potential of Orange II in splenocytes. Toxicol. Lett. 208, 239-245. doi: 10.1016/j.toxlet.2011.11.014

Yuan, Y., Zhao, X., Qiao, M., Zhu, J., Liu, S., Yang, J., et al. (2016). Determination of sunset yellow in soft drinks based on fluorescence quenching of carbon dots. Spectrochim. Acta A Mol. Biomol. Spectrosc. 167, 106-110. doi: 10.1016/j.saa.2016.05.038

Zhang, P., Zhuo, Y., Chang, Y., Yuan, R., and Chai, Y. (2015). Electrochemiluminescent graphene quantum dots as a sensing platform: a dual amplification for MicroRNA assay. Anal. Chem. 87, 10385-10391. doi: 10.1021/acs.analchem.5b02495

Zhang, T., Zhao, H., Fan, G., Li, Y., Li, L., and Quan, X. (2016). Electrolytic exfoliation synthesis of boron doped graphene quantum dots: a new luminescent material for electrochemiluminescence detection of oncogene microRNA-20a. Electrochim. Acta 190, 1150-1158. doi: 10.1016/j.electacta.2015.12.155

Zhang, Y., Tan, C., Fei, R., Liu, X., Zhou, Y., Chen, J., et al. (2014). Sensitive chemiluminescence immunoassay for E. coli O157:H7 detection with signal dual-amplification using glucose oxidase and laccase. Anal Chem. 86, 1115-1122. doi: $10.1021 /$ ac4028774 
Zhang, Y., Zhang, X. J., Lu, X. H., Yang, J. Q., and Wu, K. B. (2010). Multi-wall carbon nanotube film-based electrochemical sensor for rapid detection of ponceau $4 \mathrm{R}$ and allura red. Food Chem. 122, 909-913. doi: 10.1016/j.foodchem.2010.03.035

Zhou, J., Zhou, X., Li, R., Sun, X., Ding, Z., Cutler, J., et al. (2009). Electronic structure and luminescence center of blue luminescent carbon nanocrystals. Chem. Phys. Lett. 474, 320-324. doi: 10.1016/j.cplett.2009.04.075

Zhou, Q., Xia, G., Du, M., Lu, Y., and Xu, H. (2019). Scotch-tape-like exfoliation effect of graphene quantum dots for efficient preparation of graphene nanosheets in water. Appl. Surf. Sci. 483, 52-59. doi: 10.1016/j.apsusc.2019.03.290

Zhu, S., Zhang, J., Tang, S., Qiao, C., Wang, L., Wang, H., et al. (2012). Surface chemistry routes to modulate the photoluminescence of graphene quantum dots: from fluorescence mechanism to up-conversion bioimaging applications. Adv. Funct. Mater. 22, 4732-4740. doi: 10.1002/adfm.201201499

Zou, T., He, P., Yasen, A., and Li, Z. (2013). Determination of seven synthetic dyes in animal feeds and meat by high performance liquid chromatography with diode array and tandem mass detectors. Food Chem. 138, 1742-1748. doi: 10.1016/j.foodchem.2012.11.084

Conflict of Interest: ZL was employed by the company Pony Testing International Group and Tianjin Food Safety Inspection Technology Institute in Tianjin, China.

The remaining authors declare that the research was conducted in the absence of any commercial or financial relationships that could be construed as a potential conflict of interest.

Copyright (c) 2020 Niu, Yang, Wang, Li, Zhang, Pan, Qi, Yang, Wang and Liao. This is an open-access article distributed under the terms of the Creative Commons Attribution License (CC BY). The use, distribution or reproduction in other forums is permitted, provided the original author(s) and the copyright owner(s) are credited and that the original publication in this journal is cited, in accordance with accepted academic practice. No use, distribution or reproduction is permitted which does not comply with these terms. 